\title{
Molecular systems for the characterization of fungi of the genus Aspergillus
}

\author{
Stefano Andreoni \\ Laboratorio di Microbiologia e Virologia - Azienda Ospedaliero/Universitaria Maggiore della Carità di Novara
}

Key Words: Aspergillus, characterization, taxonomy, genotyping

\section{Sistemi molecolari nella caratterizzazione di miceti del genere Aspergillus}

\section{SUMMARY}

Taxonomy is generally considered a synonym of systematics and is traditionally divided into classification, nomenclature and identification, the process of determining whether an unknown organism belongs to one of the units defined. The new taxonomies are based on a polyphasic approach using phenotypical characters together with multigene DNA sequences. The term "polyphasic" taxonomy described the integration of all available genotypic, phenotypic, and phylogenetic information into a consensus type of classification.

These information can be used to classify fungi belong to the genus Aspergillus. Over the years, many different molecular methods have been developed for Aspergillus strain typing and to investigate the epidemiological relation between environmental and clinical isolates. Several typing methods have been described for Aspergillus species: restriction fragment lenght polymorphisms (RFLP), Random Amplification Polymorphic DNA (RAPD), Amplified Fragment Length Polymorphism (AFLP), Multilocus sequenze typing (MLST) and Random amplified microsatellites (RAMS). The advantages and disavantages of the different typing techniques are evaluated in terms of their discriminatory power, reproducibility and exchangeability, applicability, easy of use, and interpretation.

\section{INTRODUZIONE}

La caratterizzazione di microrganismi d'isolamento clinico-ambientale si basa su indagini volte a individuare specifici caratteri in grado di garantire un corretto inquadramento a livello di famiglia-genere, genere-specie, specie-sottospecie o clone. Tale caratterizzazione può basarsi sul confronto di caratteri fenotipici, quali quelli morfologico-strutturali, immunologici, chimico-metabolici e nutrizionali, e di caratteri genotipici, quali quelli estrapolabili dal DNA genomico.

La caratterizzazione genetica, attraverso l'individuazione di particolari determinanti o marcatori, rappresenta la base per la classificazione dei microrganismi: il sequenziamento completo del genoma, la possibilità di poter discriminare tra differenti genomi, così come la conoscenza della natura di specie confinanti e la loro demarcazione, risultano di fondamentale importanza nello studio della biologia evolutiva.

Attualmente sequenze genomiche complete per multipli isolati di una singola specie sono in numero piuttosto limitato e di conseguenza la tipizzazione genetica è basata ancora su metodi da considerare sub-ottimali. In aggiunta, gli stessi ricercatori che utilizzano queste metodologie, tendono ad impiegare vocabolari differenti, così come differenti risultano essere i metodi sperimentali, i marcatori molecolari, le modalità d'ana- lisi e d'interpretazione. La comprensione e il confronto dei dati è ulteriormente ostacolata dalla generale mancanza di standardizzazione delle procedure di tipizzazione, da cui una limitata riproducibilità interlaboratorio.

In ambito micologico, le tecniche di biologia molecolare hanno svariati campi d'applicazione. Schematicamente possono essere individuati due importanti filoni: l'identificazione (detection), a livello di genere/specie, del microrganismo da coltura o direttamente da campione biologico, e la tipizzazione (genotyping), a livello di specie/sottospecie, quale supporto per più definite caratterizzazioni dei microrganismi. L'identificazione e la tipizzazione possono a loro volta avere diversi indirizzi di ricerca e finalità quali la diagnostica clinica, l'epidemiologia, la tassonomia, filogenetica e genetica delle popolazioni microbiche.

Problematiche di tassonomia e di identificazione La tassonomia, nota anche come biosistematica, raccoglie gli organismi in gruppi definiti, stabilisce un'adeguata nomenclatura ed è implicata nell'identificazione di organismi precedentemente sconosciuti. La tassonomia degli Aspergilli, come del resto quella di altri micromiceti, è da ritenersi argomento di costante attualità e in continua evoluzione. Dall'ultima monografia completa su Aspergillus, scritta nel 1965 (Raper \& Fennel

\section{Corresponding author: Stefano Andreoni}

Laboratorio di Microbiologia e Virologia - Azienda Ospedaliero/Universitaria Maggiore della Carità di Novara

C.so Mazzini, 18 - 28I00 Novara - Tel.: 032I 373309I - Fax:0321 3733240

E-mail: stefano.andreoni@maggioreosp.novara.it 
1965), il genere era stato suddiviso in subgeneri e contemplava 132 specie e 18 varietà, ripartite in 18 gruppi informali. Da allora, anche con l'obiettivo di uniformare la tassonomia al Codice Internazionale di Nomenclatura Botanica, il genere è stato sottoposto a ripetute revisioni ed è attualmente suddiviso in 7 subgeneri che sono articolati in numerose Sezioni (Tabella 1).

Il numero complessivo delle specie è salito a 250 , con la possibilità concreta che possa crescere ulteriormente. La definizione di specie, passaggio fondamentale per qualsiasi inquadramento tassonomico, risulta ancora oggi controversa e soggetta a frequenti ridefinizioni.

Sulla base delle omologie genetiche, una specie è rappresentata da un "gruppo con una comune origine, composto dal più piccolo cluster di organismi tra i quali esiste un pattern (profilo) parentale di discendenza". In ultima analisi, le specie possono essere considerate come "nodi condensati" in uno spazio tassonomico oltremodo variegato e confluente. La tassonomia fornisce un'impalcatura per i "nodi" e consente di separare i rappresentanti dei nodi quali entità biologiche separate nello spazio.

Ai fini tassonomico-classificativi, per la caratterizzazione e l'identificazione dei microrganismi, in particolare a livello di specie, sono stati utilizzati nel tempo caratteri morfologici, caratteri fisiologici e metabolici e, in epoca più recente, questi aspetti sono stati integrati dal rilevamento di metaboliti e dall'analisi dei caratteri molecolari.

A tutt'oggi però non esiste un sistema che non presenti dei limiti nel riconoscimento delle specie: i criteri morfologici e fisiologici, soggetti a variazioni intra-specie, spesso sono sovrapponibili per specie geneticamente distinte, mentre i metodi molecolari non consentono di stabilire con preci- sione le linee di confine che distinguono microrganismi filogeneticamente correlati. Sebbene la maggior parte dei tassonomisti utilizzi attualmente dati derivanti da indagini molecolari, il loro peso, rispetto a quello desunto da altri metodi, è molto variabile e la maggior parte degli autori è ora propensa a ritenere che un approccio integrato, cosiddetto polifasico, sia da ritenersi il migliore.

Studi molecolari hanno dimostrato che l'analisi dei dati di sequenziamento di geni multipli o porzioni di questi (PSR: phylogenetic species recognition), possa essere una valida strategia per l'inquadramento filogenetico di una specie. Questi sistemi sono stati impiegati con successo per definire specie nei generi Fusarium e Aspergillus (3): utilizzando una serie di loci, in base all'analisi delle sequenze, sono state delineate le varie specie e le differenze fra loro; per una rapida identificazione, può poi essere utilizzata l'analisi comparativa di sequenze di un singolo locus, stabilendo un "cutoff score" dipendente dalla diversità genetica all'interno e tra specie affini. Mediante tali tecnologie, sono state investigate ad esempio due specie d'interesse clinico, A. flavus e A. fumigatus: i valori ottenuti nel confronto tra $A$. oryzae e $A$. flavus sono risultati molto simili a quelli ottenuti dal confronto intra-specifico di stipiti di A. fumigatus, dando conferma all'idea che $A$. oryzae rappresenti un particolare ecotipo di $A$. flavus ma non una specie distinta.

La filogenesi molecolare ha rilevato in un certo numero di taxa anche speciazioni criptiche, confermando che i caratteri morfologici contemplino un concetto di specie molto ampio, che non riflette la vera estensione delle divergenze evolutive e di isolamento riproduttivo, come appare nei funghi. I caratteri fisiologici, tuttavia, inclusi il grado di crescita e la produzione di extroliti, spesso

Tabella I. Classificazione corrente del genere Aspergillus* (Balajee \& Marr, 2006. Future Microbiology)

\begin{tabular}{ccl}
\hline Subgenere & Sezione & Isolati implicati in infezioni umane \\
\hline spergillus & Aspergillus & A. chevalieri \\
& Restricti & A.penicillioides, A.restrictus, A.caesiellus, \\
& A.concius \\
& Terrei & A.terreus \\
& Flavipedes & A.carneus, A.flavipes, A.niveus \\
& Nigri & A.niger, A.awamori \\
& Circumdati & A.ochraceus \\
& Flavi & A.flavus, A.oryzae, A.alliaceus, A.tamarii \\
& Candidi & A.candidus \\
\hline Fumigati & Fumigati & A.fumigatus, A.lentulus, A.viridinutans, N.fischeri, N.pseudofischeri, N.udagawae, \\
& N.hiratsukae \\
\hline Nidulantes & Nidulantes & A.clavatus, A.clavatoanicus \\
& Usti & A.ustus, A.deflectus \\
& Versicolores & A.versicolor, A.janus, A.sydowii, A.granulosus \\
\hline (comprendente & solo isolati implicati in malattie umane)
\end{tabular}


mostrano differenze che riflettono, di fatto, la filogenesi di specie confinanti. La tassonomia fungina non dovrebbe inoltre limitarsi al riconoscimento della specie e alla definizione latina, ma dovrebbe includerne la descrizione, comprendendo dati di morfologia e fisiologia, che possono essere usati non solo come mezzo per identificare un isolato ma anche per comprendere la sua biologia.

Per l'identificazione di specie, se è evidente l'orientamento verso l'impiego di sistemi molecolari, non vi è ancora un consenso diffuso su quali geni debbano essere usati a tale scopo. Per l'identificazione basata sul confronto di molecole di DNA sono state valutate numerose sequenze genetiche (regione ITS di DNA ribosomiale, subunità ribosomiale D1-D2 contenente i geni che codificano per beta-tubulina e calmodulina).

Questi barcode molecolari, per essere utilizzati con successo nell'identificazione, devono essere sufficientemente variabili per concordare con una specie, presentare bassi livelli di variabilità intraspecifica, risultare facilmente accessibili (sequenziabili da primers standard), essere relativamente corti ( $\leq 500-600 \mathrm{bp})$, semplici da sequenziare, facilmente allineabili, senza ricombinazioni.

A livello di aspergilli neri (sezione Nigri), ad esempio, per gli elevati livelli di variabilità intraspecifica, è stato evidenziato che i geni localizzati su DNA mitocondriale non soddisferebbero tutti i criteri necessari quali DNA-barcode identificativi, non risultando adatti per analisi filogenetiche. Sono stati avviati studi con singoli locus di sequenze di DNA, usando differenti loci e ci sono database estesi per geni di RNA nucleare e $ß$-tubulina. Alcune di queste regioni genetiche possono essere utilizzate come mezzo per una buona identificazione di specie, tenendo conto che l'utilizzazione di singoli locus può non garantire l'identificazione di tutte le specie di un determinato genere. Un gruppo di esperti, attraverso una valutazione dei dati di ricerca, ha presentato di recente le strategie utilizzabili per l'identificazione di Aspergilli, in particolare per specie all'interno delle sezioni Fumigati, Terrei, Usti ("Internazional workshop on Aspergillus Systematics in the genomic Era", Utrecht, 2007). Da questo gruppo di ricerca sono state date raccomandazioni per il riconoscimento inter-specie di aspergilli clinicamente rilevanti, indicando l'utilità della regione ITS per la classificazione degli aspergilli a livello di intersezione e l'utilità di analisi comparative di sequenze di loci codificanti proteine per l'identificazione di specie intra-sezione.

Come accennato precedentemente, nella definizione di specie, in questi ultimi anni, ha preso il sopravvento un concetto polifasico di specie e di tassonomia polifasica (35), basato su approccio multidisciplinare, mediante l'integrazione di tutte le informazioni derivate da indagini fenotipiche, genotipiche, filogenetiche e biologiche (Figura 1). Anche le specie di Aspergillus sono state definite mediante un approccio polifasico $(17,31)$.

A livello di Aspergillus sezione Fumigati le diversità inter ed intra-specie sono state ottenute utilizzando caratteri fenotipici (morfologia macro-microscopica, temperature di crescita, patterns di extroliti) e caratteri genotipici (RAPD-PCR, MLST: sequenziamento multi locus di geni di ß-tubulina, calmodulina, actina). Attraverso questo approccio si è potuto stabilire che la sezione Fumigati può

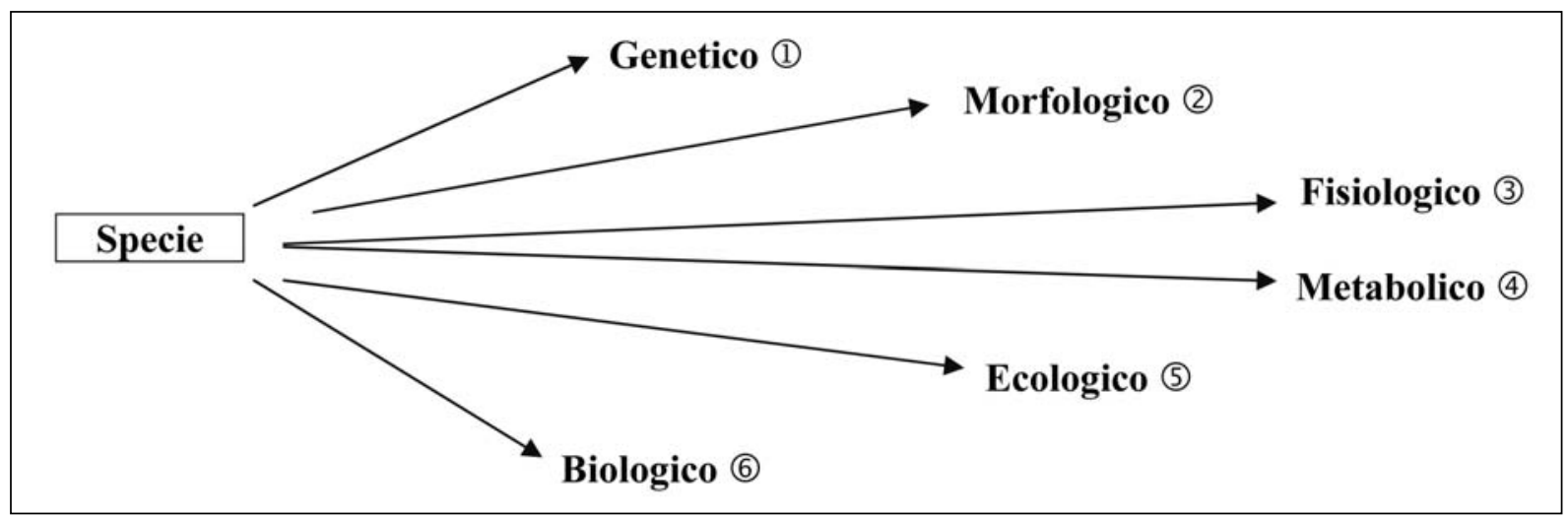

Figura I. Inquadramento tassonomico polifasico: criteri su cui si basa la differenziazione di specie

(1) genetico/filogenetico, basato su sistemi di DNA-DNA ibridazione, l'analisi di sequenze di rRNA e rDNA, ribosomiale o mitocondriale, analisi di sequenze di geni codificanti proteine ( B-tubulina, calmodulina, actina)

(2) morfologico, per il quale le specie sono distinte e riconosciute attraverso l'apprezzamento dei caratteri morfologici macroscopici delle colonie e quelli microscopici delle microstrutture fungine

(3) (4) fisiologico e metabolico, basati sulle differenze di proprietà biochimico-nutrizionali, sulle differenti temperature di crescita, sulla produzione di extroliti

(5) ecologico legato all'origine geografica, agli ecosistemi di appartenenza, agli ospiti

(6) biologico, che considera l'organizzazione dell'isolamento riproduttivo. 
essere suddivisa in 5 cladi e che le analisi comparative di sequenze delle regioni benA e cal consentono di stabilire le limitazioni di specie nella sezione Fumigati. Le specie ora accettate nella sezione Fumigati sono 30, dove non solo A. fumigatus è annoverato tra le specie di isolamento clinico ma anche A.lentulus, specie caratterizzata da alti valori di MIC in vitro verso differenti classi di antifungini, A. fumigatiaffinis e $A$. novofumigatus. In ultima analisi quindi, se i caratteri molecolari possono fornire una grande massa di informazioni sulla tassonomia dei miceti, la descrizione di una specie dovrebbe comprendere altri dati che possano essere usati non solo per l'identificazione di un isolato, ma anche per comprendere la sua biologia $(18,6)$. Per la delimitazione di specie, l'approccio polifasico, usando una combinazione di dati morfologici, fisiologici, ecologici, accanto ai dati di sequenziamento multilocus, è ritenuto attualmente il "gold standard".

Per la descrizione di una specie si raccomanda di analizzare più (2-3) sequenze genetiche (es. ITS, calmodulina, ß-tubulina, actina) e sottoporle al riconoscimento con database di riferimento.

\section{Tipizzazione genotipica}

La tipizzazione di stipiti fungini può soddisfare molteplici necessità e differenti indirizzi d'indagine. Tra le molteplici applicazioni vi sono l'epidemiologia globale e locale, lo studio di episodi epidemici, l'identificazione e la caratterizzazione dei ceppi e la conseguente costruzione di database identificativi, il monitoraggio clinico-ambientale.

I metodi di tipizzazione genotipici basati sul polimorfismo del DNA hanno progressivamente sostituito i metodi convenzionali basati sulle differenze dei caratteri fenotipici. Sensibilità ed efficienza di questi sistemi sono tuttavia controverse e con un grado di standardizzazione non ancora ottimale, tenendo conto che, nella valutazione di questi siste$\mathrm{mi}$, andrebbero sempre considerati i criteri di tipizzabilità, riproducibilità e capacità discriminatoria.

$\mathrm{Da}$ un punto di vista epidemiologico, le tecniche di tipizzazione perseguono l'obiettivo di stabilire se microrganismi appartenenti alla stessa specie isolati in tempi diversi da differenti substrati o matrici abbiano un'origine comune o, in termini biomolecolari, appartengano allo stesso clone.

La costante semplificazione delle tecnologie di supporto ha portato ad una progressiva diffusione delle applicazioni a molti laboratori.

Diversificazioni interspecie e intraspecie, tali da consentire una biotipizzazione genotipica sono state ottenute fondamentalmente: I) mediante l'individuazione di cariotipi, a seguito di separazione elettroforetica in campo pulsante di molecole di DNA di grandezza cromosomica (cariotipizzazio- ne); II) ponendo in evidenza e confrontando bande elettroforetiche di frammenti di DNA-ribosomale e di DNA-mitocondriale ottenuti con l'impiego di endonucleasi (DNA-polimorfismo da enzimi di restrizione); III) mediante ibridizzazione con sonde DNA o RNA; e, con l'introduzione delle tecniche basate sulla reazione a catena della polimerasi che garantiscono la moltiplicazione (amplificazione) di frammenti di acidi nucleici dei quali si conoscano le sequenze nucleotidiche iniziali e terminali; IV) mediante PCR fingerprinting $\mathrm{e}$, più recentemente: $\mathrm{V}$ ) mediante sequenziamento genomico.

Data la rilevanza clinica, in questi ultimi decenni sono stati sviluppati differenti metodi molecolari per la tipizzazione degli Aspergilli, in particolare per A. fumigatus (21). L'introduzione di sistemi implicanti un'amplificazione del DNA target ha comportato un considerevole incremento del segnale e conseguentemente della quantità di DNA rilevabile, garantendo un aumento della sensibilità dei sistemi di tipizzazione e delle possibilità applicative, da cui le analisi sui polimorfismi in lunghezza di sequenze tandem ripetitive microsatelliti (MLP/STR: microsatellite lenght polymophisms/short tandem repeats), le analisi su polimorfismo nella lunghezza di frammenti amplificati (AFLP: amplified fragment lenght polymorphism), o il sequenziamento di sequenze ripetitive in combinazione con polimorfismo da enzimi di restrizione (RFLP: restriction fragment lenght polymorphisms).

\section{Polimorfismo da enzimi di restrizione (RFLP).}

Partendo dal presupposto che due microrganismi possono considerarsi tanto più omologhi quanto più il loro genoma presenti le stesse sequenze di DNA, uno dei metodi più validi di tipizzazione genotipica è parso quello basato sul rilevamento e confronto di sequenze di DNA ribosomiale e mitocondriale. Ciò, a seguito dell'azione svolta da enzimi di restrizione, detti endonucleasi, capaci di produrre frammenti di DNA (frammenti di restrizione), successivamente separati per lunghezza mediante elettroforesi su gel d'agarosio.

La distanza tra le posizioni di taglio causate dagli enzimi di restrizione (siti di restrizione) risulta variabile tra una specie e l'altra, dando di conseguenza luogo a variazioni nella lunghezza dei frammenti. Ciò si riflette in una diversa posizione di alcune bande sul gel, da cui il termine polimorfismo, che comporta la realizzazione di "impronte genetiche". Questa differenza può essere usata per determinare le relazioni che intercorrono tra le varie specie con bande elettroforetiche variabili in misura tale da consentire suddivisioni degli stipiti in gruppi e sottogruppi (24). 
La sigla RFLP (dall'inglese restriction fragment length polymorphism: polimorfismo da lunghezza dei frammenti di restrizione) viene appunto utilizzata per indicare due concetti distinti: una caratteristica delle molecole del DNA che consente di distinguerle l'una dall'altra, grazie alle differenze nelle sequenze di nucleotidi che le compongono e la tecnologia che sfrutta tali caratteristiche per mettere a confronto le varie molecole di DNA.

Le prime applicazioni su Aspergillus risalgono all'inizio degli anni 90 in cui vennero utilizzati differenti enzimi di restrizione, per valutarne la capacità discriminante su stipiti di A. fumigatus, da cui emerse che gli enzimi XhoI e $S a l I$ risultavano essere quelli a più alto potere discriminante, per valutazioni d carattere epidemiologico (10), e poi ancora su $A$. flavus per cui fu possibile distinguere questa specie da altre, quali $A$. parasiticus, e $A$. nominus, senza consentire differenziazioni intraspecie (26). Ancora di recente vennero esaminate le differenze genetiche di isolati identificati morfologicamente come A. fumigatus, in cui si evidenziò che i metodi fenotipici correnti non fossero in grado di differenziare specie geneticamente distinte nell'ambito di A. fumigatus group ( $A$. lentulus, $A$. udagawae), caratterizzate da un differente pattern di sensibilità nei confronti di antifungini (5).

\section{RFLP in associazione con ibridizzazione.}

Il sistema prevede, dopo isolamento e digestione del DNA gnomico con enzimi di restrizione, che $\mathrm{i}$ frammenti di DNA vengano separati mediante gel-elettroforesi su gel d'agarosio e che il DNA venga quindi denaturato per separare $i$ filamenti complementari e trasferito su membrana di nitrocellulosa per capillarità, procedendo quindi ad ibridazione, nota come Southern-Blot, con sonde a sequenza nota (probe specifici di DNA) radiomarcate o chemiluminescenti. Il metodo comporta la dimostrazione di un polimorfismo, in forma di bande, a livello di frammenti di DNA ottenuti con enzimi di restrizione e le differenze tra i genotipi sono determinate dal numero di bande evidenziabili, subordinate al numero di siti di taglio presenti nella sequenza considerata.

Per la caratterizzazione e differenziazione di stipiti di Aspergillus d'isolamento clinico e ambientale sono state utilizzate nel tempo differenti combinazioni di enzimi di restrizione e probes (regione ITS ribosomiale, $\beta$-tubulina, ecc.): sono stati testati ad esempio elementi multicopia del genoma (Afut1, Afut2, Af4A) in combinazione con l'enzima di restrizione EcoRI, come nel caso del probe specie-specifico multicopia pAF28 su 18 isolati di $A$. flavus da differenti fonti clinicoambientali, dove il polimorfismo nella lunghezza dei frammenti di restrizione ottenuto, rivelò completa concordanza tra i patterns e furono osservati 18 fingerprints distinti.

Lo stesso probe, usato per indagare su due casi d'infezioni cutanee da A. flavus in neonati a basso peso in un Unità di terapia Intensiva Neonatale (NICU), trasportati dalla stessa ambulanza nello stesso giorno evidenziò A. flavus con lo stesso genotipo da entrambi i neonati e da varie fonti ambientali (ambulanza) (36). L'alto livello di discriminazione e di riproducibilità ottenuti con questo sistema di tipizzazione starebbe ad indicare la sua utilità per valutazioni clinico-epidemiologiche. Anche a livello di aspergilli neri venne utilizzata RFLP in combinazione con differenti probes e l'analisi della morfologia, di RFLP patterns e del profilo di metaboliti consentì di mettere in luce una nuova specie, A. vadensis (15).

RAPD (Random Amplification Polymorphic DNA). È un sistema basato su PCR in cui l'amplificazione dei frammenti di DNA non è mirata a sequenze predeterminate, bensì casuale (random). In questo caso, nella fase di amplificazione, viene utilizzato un singolo primer oligonucleotidico (sequenza aspecifica di 8-10 basi come innesco per la Taq polimerasi), in combinazione con basse temperature di annealing, che può legarsi arbitrariamente sul genoma in posizioni multiple e in modo aspecifico, da creare così numerosi frammenti: il numero e la grandezza dei frammenti ottenuti è determinata dal numero e dalla posizione dei siti di annealing. I prodotti di amplificazione, mediante elettroforesi su gel di agarosio, vengono separati in base al loro peso molecolare, ottenendo così, per ogni stipite saggiato, un profilo di bande caratteristico, variabile nel numero e nella lunghezza, in relazione ai diversi punti di appaiamento dei primer. Isolati non correlati generalmente forniscono differenti pattern di bande e il sistema è in grado di individuare polimorfismo presente anche tra isolati della medesima specie. Il potere risolutivo di questa metodologia è più basso rispetto a sistemi con sequenze target più specifiche e la riproducibilità è strettamente influenzata dalle condizioni operative. Il vantaggio principale della tecnica RAPD è che, poiché i primers si legano in maniera random nella sequenza, non dando informazioni né riguardo al tipo di gene né al tipo di sequenza amplificata, non è necessaria alcuna conoscenza specifica della sequenza target, non richiedendo DNA di elevata purezza e garantendo una metodologia semplice e rapida. La tecnologia RAPD è inoltre relativamente poco costosa ed è quella largamente più utilizzata per la tipizzazione di Aspergillus. A livello di aspergilli, mediante RAPD-PCR e 
attraverso l'impiego di un numero notevole di primers oligonucleotidici, venne verificata e confermata la capacità discriminativa e il potenziale utilizzo come markers genetico su isolati di $A$. fumigatus (1), di A. flavus (14), di A. ustus (29) e di $A$. terreus. Sempre mediante RAPD-PCR, venne valutato il potere discriminante di 5 primers per 3 specie di Aspergillus (A. fumigatus, A. niger. e A. fla$v u s)$ su isolati clinici e stipiti di riferimento, in cui risultò che R108 fosse da ritenere il primer più adatto per l'identificazione e la caratterizzazione di Aspergillus species (28).

\section{AFLP}

\section{(Amplified Fragment Length Polymorphism).}

Sviluppata nei primi anni 90 da Keygene e descritta per la prima volta da Vos nel 1995, AFLP è un sistema di marcatura molecolare basato sull'amplificazione selettiva di frammenti di restrizione del DNA genomico. Tale tecnologia si sviluppa su steps successivi che prevedono: a) l'estrazione e la digestione del DNA cellulare tramite una o più endonucleasi di restrizione (generalmente 2, con differenti frequenze di taglio); b) la selezione di un subset di frammenti di restrizione attraverso il legame, ad entrambe le estremità, con "adattatori" molecolari" (doppi filamenti di DNA sintetico), che fungono da primer e una prima amplificazione (pre-amplificazione) selettiva di alcuni di questi frammenti con i primers complementari alle sequenze degli adattatori, ma estesi alla terminazione $3^{\circ}$ di uno o più nucleotidi, arbitrariamente scelti (pochi nucleotidi all'interno del frammento del sito di restrizione); c) una successiva amplificazione con primer marcati (marcatore fluorescente), la cui sequenza è identica a quella dei primers usati precedentemente ma estesa in $3^{\circ}$ di uno o due nucleotidi, scelti arbitrariamente. Il numero di frammenti che verranno generati potrà essere modulato mediante l'estensione del primer di amplificazione a livello $3^{\circ}$ terminale con uno $\mathrm{o}$ più nucleotidi selettivi. I prodotti di amplificazione sono quindi separati su un gel di poliacrilamide denaturato, ad alta risoluzione, e visualizzati, mediante metodologie fluorescenti o radioimmunologiche. Con questo sistema viene ottenuto un complesso di pattern di bande di DNA di 50-500 bp e le variazioni tra i differenti isolati derivano dalle differenze nel numero e nella posizione dei siti di riconoscimento degli enzimi di restrizione nel DNA genomico.

La tecnologia AFLP, altamente sensibile, riproducibile, con un alto potere discriminante, è in grado di rilevare contemporaneamente (tra 50 e 100 frammenti) vari polimorfismi in differenti regioni genomiche e consente di studiare le diversità genetiche delle specie sotto il profilo dell'evolu- zione del genoma, della filogenesi e della distribuzione geografica. Di conseguenza AFLP è impiegata largamente negli studi tassonomici, per l' $i$ dentificazione di variazioni genetiche negli stipiti $o$ in specie strettamente correlate di piante, funghi, animali o batteri. Presentato come uno tra i principali strumenti per finalità di tipizzazione, AFLP consente di garantire differenziazioni a livello di specie e sottospecie, particolarmente utile nel caso di microrganismi morfologicamente molto similari come nella sezione Fumigati. In uno studio (37), per stabilire se funghi d'origine ambientale (sorgenti d'acqua e aria) potessero avere un ruolo nella patogenesi di aspergillosi invasive, venne approntata una caratterizzazione molecolare mediante AFLP (EcoRI e MseI con tre nucleotidi selettivi) di 96 isolati di A. fumigatus di origine clinica (aspergillosi provata, probabile, possibile) e ambientale durante un periodo di 18 mesi. In base al fingerprints genomico gli isolati ambientali vennero divisi in due cluster e il confronto con gli isolati clinici suggerì che i pazienti con aspergillosi invasiva potessero essere stati infettati da stipiti ambientali. Da queste osservazioni si evinse la necessità di misure di controllo adeguate per prevenire aspergillosi invasive in pazienti a rischio infettivo elevato. In altre esperienze, con la medesima combinazione di enzimi ma con differenti nucleotidi selettivi, venne analizzata la diversità genetica nelle sezioni Flavi e Nigri $(25,27)$. Con questi studi venne dimostrato come AFLP possa essere un eccellente metodo di tipizzazione, a livello di specie e sottospecie, nell'ambito di Aspergillus.

\section{STRs (Short Tandem Repeats) (ripetizioni tandem brevi) (Microsatelliti)}

In genetica e biologia molecolare si definiscono ripetizioni tandem tutte le regioni di DNA costituite da sequenze di due o più nucleotidi ripetute, una di seguito all'altra, che possono essere completamente identiche o parzialmente degenerate. Col termine microsatelliti vengono indicate le regioni di DNA caratterizzate da una stessa sequenza e dove le sequenze ripetute sono adiacenti tra loro. Le sequenze possono variare in lunghezza da 2 a 16, fino a 50 copie di basi azotate (bp) e generalmente si collocano in regioni introniche non codificanti. Microsatelliti o sequenze tandem brevi (STR) sono diffusamente presenti nel genoma di organismi eucarioti, inclusi molti funghi, dove giocano un ruolo importante nel generare variabilità. I microsatelliti, presentando elevato polimorfismo all'interno di ciascuna specie, possono essere utilizzabili come marcatori molecolari, risultando un ottimo strumento per il fingerprinting. In questo caso, un polimorfismo 
da STR si manifesta quando STR loci omologhi differiscono nel numero di ripetizioni tra stipiti. L'uso di STR come marker genetico offre numerosi vantaggi, quali facilità di amplificazione, elevato grado di polimorfismo, opzioni multiplex, potere discriminante molto elevato, elevata riproducibilità, risultati poco ambigui e facilmente confrontabili, possibilità di rilevare campioni misti. Una volta che le sequenze vengono amplificate possono essere analizzate attraverso gelelettroforesi o elettroforesi capillare. Nel primo caso il DNA può essere visualizzato o mediante colorazione argentica (a risoluzione non alta, sicura e poco costosa), mediante etidio-bromuro (più sensibile ma meno sicura) o mediante colorazioni fluorescenti (più sensibili, sicure ma costose). Anche gli strumenti che visualizzano frammenti mediante elettroforesi capillare utilizzano coloranti fluorescenti. Gli isolati possono essere distinti in base alle differenze sul numero di ripetizioni. L'elemento chiave nell'uso di microsatteliti è quello di traslare in mobilità elettroforetica il frammento ottenuto, tenuto conto però che questa mobilità dipende da molti fattori come la presenza/assenza di composti denaturati, il tipo di matrice usata, l'esatta composizione delle basi, la sequenza dei frammenti e la temperatura della corsa (12).

La prima applicazione di questa metodologia su A. fumigatus risale al 1998, con l'impiego di 4 markers dinucleotidici (7). I microsatelliti contenenti le sequenze marker vennero ricavate da uno screening di librerie genomiche di DNA, da cui si ottenne un pannello di 4 sequenze dinucleotidiche ripetute. Anche per A. flavus e A. parasiticus sono stati caratterizzati sette loci microsatellite (33), così come per $A$. niger (sei) e per E. nidulans (sette). Recentemente è stato descritto un pannello microsatellite denominato STRAf (STR for $A$. fumigatus) che utilizza 9 sequenze tandem markers, contenenti anche tri e tetranucleotidi. Con questi marcatori, mediante l'impiego di una multiplex multicolor, fu possibile analizzare in breve tempo un gran numero di isolati.

Il numero superiore di loci comportò un potere discriminante superiore (12).

Geni contenenti ripetizioni tandem mini/microsatellite sono componenti altamente dinamiche del genoma. La frequenza di fenomeni di ricombinazione all'interno di queste sequenze tandem, col conseguente cambio nel numero di ripetizioni, può portare ad alterazioni delle sequenze aminoacidiche delle corrispondenti proteine. Nei batteri e nei lieviti questo fenomeno, in associazione con proteine del cell-wall, può comportare alterazioni dell'immunogenicità e della patogenesi. In uno studio recente vennero analizzate sequenze tan- dem ripetitive di $A$. fumigatus correlabili alla codifica di proteine di parete. Nell'analisi del genoma di A. fumigatus vennero individuati 292 geni con sequenze ripetitive e 14 di 30 geni selezionati mostrarono variazione nella grandezza delle regioni ripetitive tra 11 isolati clinici di A. fumigatus. Quattro di questi geni, Afu3g08990, Afu2g05150, $A f u 4 \mathrm{~g} 09600$, e $A f u 6 \mathrm{~g} 14090$, codificavano per potenziali proteine del cell wall e presentavano un certo numero di unità aminoacidiche ripetitive.

La delezione di uno di questi geni, Afu3g08990, generò un fenotipo caratterizzato da una rapida germinazione conidiale e da una ridotta adesività a matrici extracellulari, suggestive per un'alterazione delle caratteristiche del cell wall. Queste osservazioni suggerirono che un subset di proteine di superficie di $A$. fumigatus possa essere ipervariabile in relazione a fenomeni di ricombinazione a livello delle ripetizioni tandem (23).

\section{MLST (Multilocus sequenze typing).}

Nell'ultima decade i sistemi basati sull'amplificazione seguita dal sequenziamento e dalla comparazione di target nucleici fungini sono passati da una fase di ricerca ad una fase d'applicazione clinico-diagnostica e attualmente sono da ritenersi un nuovo "gold standard molecolare" per l'identificazione di specie fungine. In breve, con MLST si mettono a confronto sequenze nucleotidiche di frammenti di una serie di geni (da sei a dieci): il sistema poggia sull'amplificazione di una regione selezionata del DNA genomico (target locus), mediante PCR, seguita dal sequenziamento degli ampliconi risultanti. Una volta ottenuta la sequenza, questa può essere confrontata con sequenze depositate in librerie genetiche di riferimento. In base a tale confronto, viene stabilita una percentuale di identificazione, che è rappresentata da un singolo score numerico derivato da ogni coppia di sequenze allineate e che rappresenta (misura) il numero di paia nucleotidiche identiche per la lunghezza dell'allineamento. Nell'analisi dei dati a tutte le sequenze uniche viene assegnato un numero allelico, abbinato ad un profilo allelico. La combinazione di numeri allelici (7) fornisce la sequenza tipo (ST: sequenze type). Un ST è definito come la combinazione di alleli ad un determinato locus. Se vengono trovati nuovi alleli e ST essi vengono inseriti nel database. Stipiti correlati hanno la stessa ST o differiscono in uno o due alleli. Nella fase finale attraverso la comparazione dei profili allelici vengono stabilite le correlazioni tra isolati. Le sequenze vengono comparate per ogni frammento dei geni scelti e i ceppi con identiche sequenze vengono assegnati allo stesso ST. Per ogni gene le differenti sequenze presenti in una specie vengono assegnate come allele distin- 
to e, per ogni isolato, gli alleli per ognuno dei loci definisce il profilo allelico o sequenza tipo (ST). I cutoff scores per l'identificazione di specie sono arbitrari e possono variare in relazione a numerosi fattori, quali la qualità della sequenza, il numero e l'accuratezza dei database esistenti per la stessa specie, la lunghezza del frammento sequenziato e il software impiegato. Allo stato attuale non esiste uno studio definitivo che possa stabilire un cutoff assoluto per l'identificazione di specie e un consensus su come definire una specie impiegando tale metodologia comparativa (3).

Il successo di una strategia di sequenziamento comparativo per l'identificazione di un range esteso di isolati clinici fungini si basa sulla scelta di un locus appropriato. L'utilizzo di tecniche di sequenziamento deve prevedere che il target genetico contenga regioni altamente conservate che possano fungere da sito di legame per i primers, affiancate da sequenze sufficientemente variabili da consentire la differenziazione a livello di genere/specie (38). I geni target dovrebbero essere ortologhi (es evolvere da un comune discendente), avere alti livelli di variazione interspecie combinati con bassi livelli di variazione intraspecifica e idealmente non dovrebbero subire ricombinazione. I geni target, inoltre, dovrebbero essere presenti in un alto numero di copie per incrementare la sensibilità della PCR prima dell'analisi delle sequenze. In aggiunta il target dovrebbe essere facile da amplificare e sequenziare usando un set di primer standardizzati "universali". Infine, il frammento di DNA amplificato dovrebbe rientrare nel range di grandezza ottenibile con la maggior parte dei comuni sequenziatori automatici utilizzati (da 600 a 800 bp) ed essere allineabile con le sequenze in database disponibili per le comparazioni.

Non mancano esperienze in merito all'applicazione del sequenziamento multilocus su miceti del genere Aspergillus. A livello della sezione Fumigati, ad esempio, MLST ha portato alla descrizione di una nuova specie potenzialmente patogena, A. lentulus (4). Più recentemente, mediante MLST, è stato descritto uno schema per A. fumigatus con l'impiego di sette geni selezionati per tipizzare 100 isolati clinici e ambientali da cui vennero evidenziati 30 STs (2). Mediante sequenziamento multilocus fu possibile distinguere $A$. lentulus da $A$. fumigatus: i dati di sequenza mostrarono infatti che il gene codificante $\beta$-tubulina, benA, risulta avere una alta variabilità interspecie in regioni introniche, mantenendo stabilità tra gli isolati della stessa specie. Questi dati vennero usati per sviluppare una PCR-RFLP (PCRrestriction fragment length polymorphism) per distinguere rapidamente $A$. fumigatus, $A$. lentulus, e $N$. udagawae. La digestione dell'amplicone benA con $B c c \mathrm{I}$ fu in grado di generare patterns di bande uniche, i cui risultati furono validati mediante l'analisi di sequenze depositate in GenBank database. Da questa esperienza PCRRFLP di benA risultò quindi un metodo semplice per l'identificazione di Aspergillus spp. all'interno della sezione Fumigati (32).

In uno studio recente l'analisi mediante sequenziamento della regione polimorfica del gene che codifica per la proteina di superficie del cell-wall Afu3g08990 (denominato CSP), su 55 A. fumigatus d'isolamento clinico da 6 epidemie nosocomiali di aspergillosi invasive, evidenziò che la diversità genetica era legata sia alla presenza di ripetizioni tandem che a mutazioni puntiformi. Con questa indagine venne dimostrato che una tipizzazione mediante sequenziamento di un singolo locus (tipizzazione CSP) fosse in grado di rilevare variabilità tra gli isolati clinici, dimostrando un potere discriminante pari a quello di RFLP ma attraverso procedure più semplici e accessibili (6).

Ancora di recente, in uno studio di sorveglianza, un gran numero d'isolati di Aspergillus da pazienti trapiantati con aspergillosi invasiva provata o probabile, vennero sottoposti a sequenziamento, usando le regioni ITS e di ß-tubulina, per determinare la distribuzione delle varie specie in ambito clinico (3). A. fumigatus risultò la specie predominante, seguita da $A$. flavus e A. niger. Vennero però individuate anche nuove specie in ambito clinico come A. lentulus e A. calidoustus, caratterizzate da MIC elevate nei confronti di numerosi antifungini, e $A$. tubingensis, membro di A. niger complex.

\section{Altre tecniche di tipizzazione. \\ RAMS (Random amplified microsatellites) è una} tecnica basata su una PCR che utilizza primers contenenti sequenze microsatelliti. In questo caso viene amplificato il DNA di due estremità di micro satelliti e i prodotti della PCR vengono separati successivamente mediante elettroforesi. Questa tecnica differisce poco dalla RAPD ed è stata usata su A. fumigatus e A. flavus. SSDP (sequenze-specific DNA primers) rappresenta anch'essa una variante RAPD nella quale frammenti di DNA in grado di differenziare isolati di A. fumigatus vengono selezionati e sequenziati e in base alle sequenze ottenute viene costruito un set specifico di primers. IGS-PCR (Intergenic spacer-analysis) è una PCR nella quale i primers agganciano una regione tra piccole e grandi subunità di geni RNA-ribosomiali. Il genoma di un fungo contiene circa 100 copie altamente conservate di questi geni. Attraverso le variazioni in lunghezza di questa regione intragenica è possibile 
differenziare pattern differenti.

Recentemente, utilizzando una piattaforma Luminex xMAP (Luminex Corp., Austin, TX), venne approntato un dosaggio multiplex su Aspergillus per la rapida identificazione di Aspergilli di interesse clinico, attraverso marcatura di Aspergillus specie a livello di sezione (species complex) con probes specifici della regione ITS (16), non idonei per l'identificazione all'interno del complex (es Aspergillus lentulus e Neosartorya pseudofischeri). Schematicamente tale sistema si basa su l'utilizzo di un insieme di microsfere colorate internamente con varie proporzioni di coloranti rossi ed infrarossi fluorescenti in grado di produrre differenti segnali spettrali rilevati da due laser. Probes specie-specifici possono essere legati a queste microsfere e testati impiegando PCR-ampliconi biotinilati. Gli stessi autori procedettero successivamente allo sviluppo di un dosaggio, sempre basato sulla stessa tecnologia Luminex, volto alla rapida differenziazione di Aspergillus fumigatus da altre specie all'interno dell'A. fumigatus species complex (sezione Fumigati), attraverso un probe, derivato da sequenze di una regione della $\beta$-tubulina (GenBank), specifico per A. fumigatus e dotato di una sufficiente capacità discriminativa per differenziare le specie all'interno della sezione. $\mathrm{Su}$ questa base il dosaggio A. fumigatus-specific Luminex (AFSL) venne utilizzato per determina- re la distribuzione globale delle specie all'interno del complex analizzando 499 isolati clinici di $A$. fumigatus species complex raccolti nel mondo con il programma di sorveglianza ARTEMIS dal 2006 al 2009 (16). Da questo studio emerse che nell'ambito di stipiti morfologicamente identificati come A. fumigatus species complex sarebbero presenti specie non- $A$. fumigatus, quali $A$. lentulus, Aspergillus udagawae, e Neosartoria pseudofischeri.

\section{Targets genetici}

Numerose osservazioni avrebbero dimostrato che, per il sequenziamento comparativo, i targets genetici del segmento nucleare ribosomiale bene si adattano all'identificazione di Aspergillus $e$ Fusarium, a livello di specie complex, e per la maggior parte delle specie del genere Mucorales. La struttura generale della regione ribosomiale di rRNA di cellule fungine consiste di 4 geni ribosomiali (una piccola subunità a $18 \mathrm{~S}$, una subunità a $5.8 \mathrm{~S}$, una grande subunità a $25-28 \mathrm{~S}$, una subunità a $5 \mathrm{~S}$ ), separati da regioni introniche ITS. I loci più comunemente utilizzati per studi molecolari sono rappresentati dalle regioni ITS1 e ITS2 tra le subunità $18 \mathrm{~S}$ e $28 \mathrm{~S}$ e una regione di circa 600 copie di basi (D1-D2) della subunità 25-28S (Figura II).

La regione ITS soddisfa la maggior parte dei requisiti di marker genetico "universale" poiché

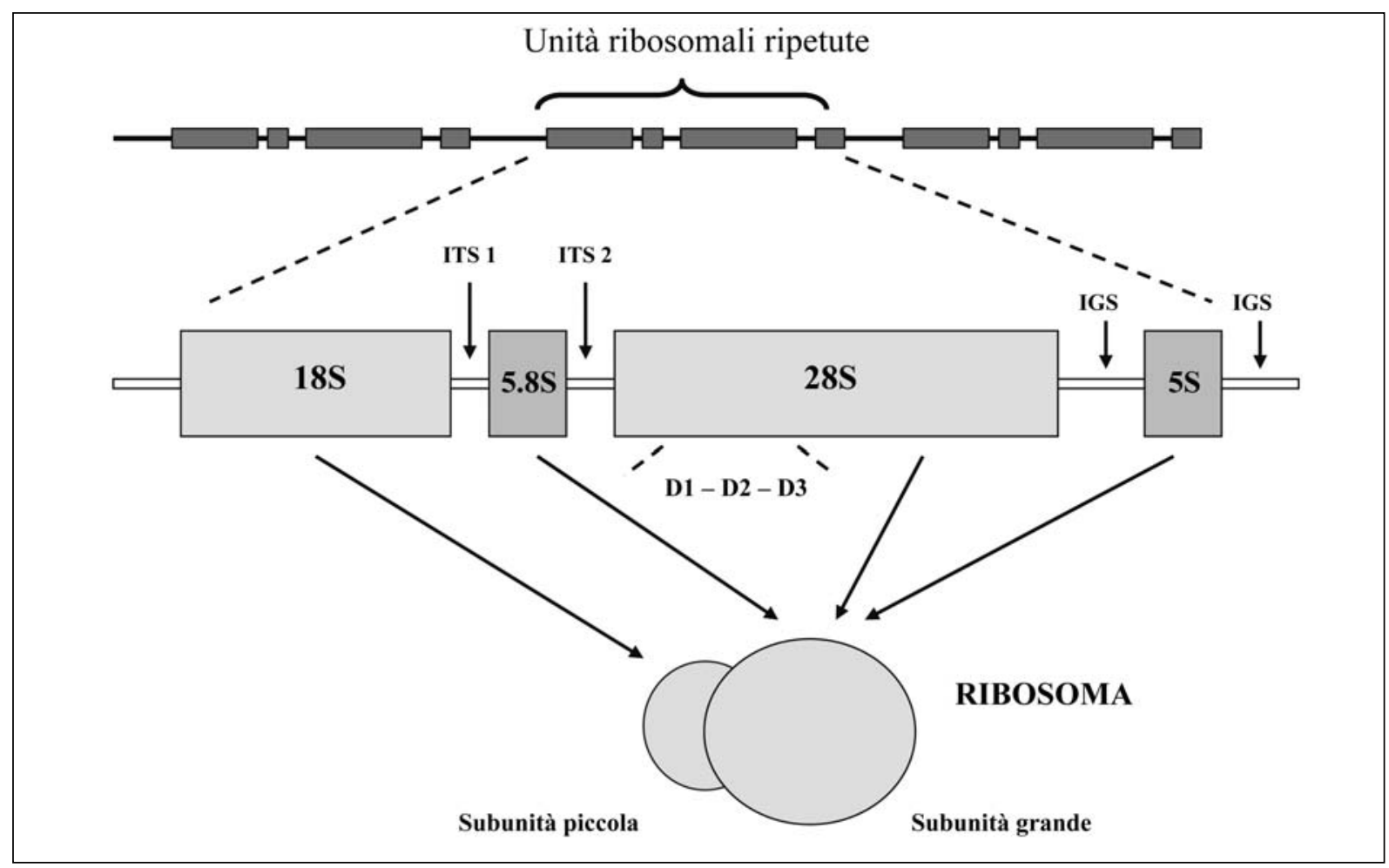

Figura II. Organizzazione strutturale dei geni fungini ribosomiali

ITS: Internal Transcribed Spacer regions

IGS: Intergenic Spacer regions 
per la maggior parte dei funghi può essere facilmente amplificata, è altamente conservata, è presente in copie multiple nel genoma fungino, presenta una sufficiente risoluzione ai fini tassonomici e ha il vantaggio addizionale che GenBank (http://www.ncbi.nlm.nih.gov), European Molecular Biology Laboratory nucleotide sequence database (http://www.ebi.ac.uk/embl/) e DNA Data Bank of Japan (http://www.ddbj.nig.ac.jp/), principali banche dati attualmente disponibili, contengono un grande numero di sequenze da questo locus, consentendo facili comparazioni per ceppi isolati sconosciuti (3). Esiste quindi un sostanziale consenso sull'impiego del sequenziamento ITS come step iniziale per l'identificazione dei miceti filamentosi: 1'International Subcommission on Fungal Barcoding ha proposto infatti la regione ITS come principale barcode fungino o come regione di default per l'identificazione di specie (http://www.allfungi.com/its-barcode.php).

In un'esperienza, identificazione e tipizzazione di Aspergillus species vennero approntate mediante amplificazione delle regioni ITS1 e ITS2, usando come primers rRNA (18S e 28S): le regioni ITS1 e ITS2 di aspergilli di isolamento clinico furono amplificate, sequenziate e comparate con stipiti di riferimento e sequenze presenti in GenBank. La variazione intraspecie degli isolati clinici e degli stipiti di riferimento fu minima. Gli autori giunsero alla conclusione che l'applicazione clinica di questo sistema potrebbe comportare una diagnosi precoce per pazienti con infezione aspergillare (19). L'utilizzo delle regioni ITS ai fini identificativi si accompagna ad alcuni svantaggi che includono (I) un'insufficiente ipervariabilità per distinguere le varie specie nella sezione Aspergillus e nel complex Fusarium; (II) l'incapacità di distinguere tra specie fortemente correlate per un'insufficiente differenziazione nucleotidica (es. Aspergillus lentulus e Aspergillus fumigatus); (III) la mancanza di un consensus sulle percentuali di identità delle sequenze (IV); problemi legati alle sequenze ITS depositate nei databases di riferimento (librerie genetiche) (es GenBank/EMBL/DDBJ).

L'identificazione basata sul confronto di sequenze nucleotidiche può infatti risultare valida solo a condizione di disporre di ricco e valido database, contraddistinto dalla presenza di sequenze di ceppi di riferimento o in ogni caso di sequenze rigorosamente validate, in termini di nomenclatura, e appartenenti ad una grande varietà di specie target. Il principale database impiegato è GenBank, che contiene un gran numero d'informazioni tra cui numerose inedite o non validate. All'interno di GenBank sono stati evidenziati nel tempo errori di sequenze fungine pari al $20 \%$.
Per superare questo problema sono stati creati databases di specifiche sequenze e per particolari gruppi fungini, basati su sequenze qualitativamente controllate, in particolare per ascomiceti e basidiomiceti d'importanza industriale. [Fusarium spp. (FUSARIUM-ID: http://fusarium.cbio.psu.edu), Phaeoacremonium spp. (http://www.cbs.knaw.nl/phaeoacremonium/bio lomics.aspx), Trichoderma spp. (http://www.isth.info/morphology.php).

Databases per funghi d'importanza clinica sono disponibili presso il CBS Fungal Biodiversity Centre and at the Westmead Millennium Institute, University of Sydney (http://www.mycologylab.org/biolomicsid.aspx)]. Tassonomicamente il genere Aspergillus è diviso in sette subgeneri, ulteriormente divisi in numerose sezioni" (es. il subgenere Fumigati comprende due sezioni: Fumigati e Cervini). Aspergilli clinicamente rilevanti si collocano in numerose sezioni nell'ambito dei sette subgeneri. Specie di rilevanza clinica come A. fumigatus e altre meno comuni come Neosartorya fischeri e A. lentulus si collocano ad esempio all'interno della sezione Fumigati nel genere Aspergillus.

In base a questo schema classificativo si possono stabilire due livelli di identificazione: (I) a livello di specie complex, es. discriminazione di $A$. fumigatus complex (subgenus Fumigati, section Fumigati) da $A$. flavus complex (subgenus Circumdati, section Flavi), e (II) a livello di specie all'interno della sezione; es. discriminazione di $A$. fumigatus da $A$. lentulus (entrambi membri della sezione Fumigati, subgenere Fumigati). Impiegando l'analisi di sequenze della regione ITS, si può rapidamente collocare un aspergillo all'interno della rispettiva sezione (es. Aspergillus ustus nella sezione Usti o Aspergillus terreus nella sezione Terrei). Di contro l'identificazione all'interno della sezione, per la limitata variabilità della regione ITS, può risultare difficoltosa, anche se studi recenti hanno dimostrato però che l'analisi di sequenze di regioni codificanti proteine $(\beta-$ tubulina, calmodulina), possono consentire l'identificazione all'interno delle sezioni Fumigati, Usti, Nigri, e Terrei.

Con il sequenziamento completo del genoma di 8 specie di aspergillo in fase di realizzazione, vi sarà la possibilità di produrre dati per molti loci utili per la caratterizzazione di aspergilli. Quando vengono stabiliti quali loci e/o il numero dei loci da utilizzare va considerato a quale livello si pone la rilevanza dell'identificazione dell'isolato e se per un laboratorio di microbiologia clinica sia necessaria un'identificazione a livello di specie o risulti sufficiente un'identificazione a livello di genere o specie complex. 
Per isolati fungini da campioni clinici, specialmente da siti sterili di pazienti immunocompromessi, è ormai accertata l'importanza di un'identificazione di specie, a garanzia di un supporto terapeutico adeguato e in considerazione di valutazioni epidemiologiche corrette. Il significato clinico di un'identificazione a livello di specie appare evidente in alcuni casi come ad esempio per A. terreus vs A. fumigatus per la differente sensibilità ad amfotericina $\mathrm{B}$; ma molto meno evidente in altre situazioni a livello di Fusarium, Mucorales e anche a livello di specie-complex di aspergilli. Vari studi hanno mostrato differenze specie-specifiche nella sensibilità ad antifungini all'interno della sezione Fumigati, mentre altri studi hanno dimostrato poca o nessuna differenza nella sensibilità ad antifungini all'interno della sezione Usti e Terrei. Allo stesso modo, poche differenze nella sensibilità risulterebbero per il genere Fusarium, mentre sono state osservate considerevoli variazioni intraspecifiche nella sensibilità a polienici e azolici in vitro e in vivo in modelli animali per Mucorales.

Ancora oggi il sequenziamento di DNA target può comportare incertezze nella collocazione delle sequenze ottenute in un gruppo tassonomico definito. Nel maggio del 2008, il Clinical and Laboratory Standards Institute (CLSI) ha pubblicato un documento, "Interpretive Criteria for Identification of Bacteria and Fungi by DNA Target Sequencing" (MM18-A), per indirizzare l'analisi di sequenze nelle pratiche di laboratorio. In particolare questo documento fornisce un approccio sistematico e uniforme per l'identificazione di funghi attraverso un vasto range di sequenze di DNA target. Il documento stabilisce linee guida per la definizione di primer, i controlli di qualità per amplificazione e sequenziamento, la valutazione dei database di riferimento. Tali linee guida raccomandano che per determinati taxa i laboratori clinici riportino i risultati del sequenziamento a livello di genere o specie-complex. Il documento CLSI è centrato sulla regione ITS come target. Similarmente al CLSI, l'ISHAM working group sottolinea le differenze tra specie complex e specie individuali e presenta targets alternativi che possano consentire identificazioni specie-specifiche in Aspergillus e Fusarium, quando tali informazioni siano necessarie.

Attraverso l'attività svolta da questi gruppi di lavoro si è giunti alla conclusione, sostanzialmente condivisa che, se l'obiettivo è quello di identificare un microrganismo sconosciuto, l'utilizzo della regione ITS è una scelta sensata per l'identificazione di specie complex all'interno dei generi Aspergillus, Fusarium e di molte specie nell'ambito Mucorales. L'accettazione dell'impiego di
ITS come locus di default nei laboratori di microbiologia clinica avrebbe anche il vantaggio di rafforzare gli sforzi commerciali su questa strategia. Sempre questi gruppi di lavoro hanno proposto un algoritmo per identificazioni a livello di specie basato su valutazioni di caratteri morfologici e molecolari in combinazione, indicando nel sequenziamento di regioni codificanti proteine il mezzo migliore per identificazioni all'interno dei complex (21). In ultima analisi sono state proposte le seguenti raccomandazioni:

a) il termine "specie complex" in alternativa al termine "sezione,"

b) l'uso di sequenze della regione ITS per l'identificazione di Aspergillus a livello di specie complex,

c) l'analisi comparativa di sequenze della regione di $\beta$-tubulina per l'identificazione all'interno del complex.

Con tale schema di identificazione il termine "complex" dovrebbe collocare l'isolato all'interno del complex ma non identificare la specie nel compelx.

Attualmente non esistono consensi a livello internazionale su quali valori di cutoff dovrebbero essere applicati per l'identificazione della stessa specie e quindi è ancora richiesto un certo grado d'interpretazione. Analizzando i dati di sequenze ITS da più di 600 isolati di Aspergillus da tre differenti laboratori (S. A. Balajee, W. Meyer e A. Velegraki) e impiegando, per il confronto di sequenze, sia database "in-house" che GenBank/EMBL/DDBJ database, per il genere Aspergillus è stata proposta un'identità da 94 a 100\% come base per la conferma d'identificazione a livello di specie complex, per stipiti da validare. Quando si appronta un'analisi di sequenze è fondamentale sapere che le percentuali di score di identità ottenute usando GenBank/EMBL/DDBJ, sono influenzate da numerosi fattori, inclusi la qualità delle sequenze, il numero e l'accuratezza dei records esistenti per la stessa specie e locus, e la completezza della sequenza a doppia elica. Per incrementare l'accuratezza dei dati di sequenze viene enfatizzata l'importanza del completamento dei record dei database. Il nome teleomorfo, se noto, dovrebbe essere incluso e disponibile e i nomi delle specie dovrebbero seguire le indicazioni del Code of Botanical Nomenclature. L'identità delle specie e l'accuratezza delle sequenze dovrebbero essere confermate da altre fonti come Centraalbureau voor Schimmelcultures (http://www.cbs.knaw.nl), l'UK National Collection of Pathogenic Fungi (http://www.hpacultures.org.uk), o Mycobank (http://www.mycobank.org). 


\section{Confronto più metodi genotipici}

In questi ultimi decenni non mancano, a livello di letteratura internazionale, segnalazioni di confronti tra differenti sistemi di tipizzazione.

Nel 1999 vennero analizzati ceppi di A. fumigatus isolati da 4 pazienti con aspergillosi invasiva e da fonti ambientali mediante 3 metodi molecolari: MLEE (multi-locus enzyme electrophoresis), RAPD (random amplified polymorphic DNA) e SSDP (sequence-specific DNA primers).

Per la RAPD l'uso del primer NS3 determinò patterns sufficientemente polimorfici da differenziare gli isolati di 3 pazienti.

I 3 sistemi combinati mostrarono una maggiore capacità discriminante rispetto ad un impiego separato. L'indagine dimostrò la variabilità genotipica di A. fumigatus e il notevole polimorfismo tra gli isolati e tra le colonie all'interno dei vari campioni. Solo per un paziente fu possibile ipotizzare un'acquisizione nosocomiale dell'aspergillosi. I risultati suggerirono anche almeno 3 infezioni multiple tra i 4 pazienti (30).

Sempre nello stesso periodo, in un'altra esperienza, vennero investigate le fonti d'infezione e le correlazioni epidemiologiche di ceppi di A. fumigatus isolati da colonizzazione bronchiale e aspergillosi invasiva di 4 pazienti trapiantati e da numerose fonti ambientali per un totale di 91 campioni. Gli isolati vennero analizzati con tre sistemi: MLEE, RAPD e SSPD i cui dati combinati dimostrarono maggiore capacità di differenziazione rispetto ad un'analisi separata, confermando la grande variabilità genotipica di $A$. fumigatus. A livello dei campioni venne dimostrato un elevato grado di polimorfismo in ogni paziente.

In particolare, per un paziente le correlazioni tra isolati suggerirono un'origine nosocomiale, anche se la fonte rimase poco chiara, mentre venne accertata la possibilità di infezioni multiple per almeno 3 pazienti (30).

Negli anni successivi, in un'indagine epidemiologica su A. fumigatus in campioni clinici, in pazienti con aspergillosi invasiva, vennero messe a confronto tre sistemi di tipizzazione: RAPD, SSDP e MSP. Su 52 isolati vennero riscontrati rispettivamente $8,9,14$ genotipi e 25 da una lettura combinata con multilocus enzyme electrophoresis (MEE). La combinazione di più metodologie risultò prestarsi meglio ad una discriminazione tra stipiti rispetto ad analisi separate (8).

In un'indagine del 2002 (22) 49 stipiti di A. fumigatus d'origine nosocomiale furono tipizzati, mettendo a confronto un metodo basato su polimorfismo da enzimi di restrizione (RLFP) con Afut 1 ibridazione, con 3 sistemi di tipizzazione molecolare basati su PCR, quali random amplified polymorphic DNA analysis (RAPD), sequence-speci- fic DNA primer analysis (SSDP) e polymorphic microsatellite markers analysis (PMM). I sistemi di tipizzazione furono valutati in relazione al potere discriminante, alla tipizzabilità e riproducibilità, alla facilità d'esecuzione ed interpretazione. I 4 sistemi mostrarono $100 \%$ di tipizzabilità; PMM e RLFP risultarono dotati di potere discriminante più alto, dove SSDP si dimostrò il sistema più facile da approntare ed interpretare.

Per RAPD, un livello elevato di potere discriminante si ottenne utilizzando una combinazione di 3 primers. Dall'analisi complessiva dei dati risultò che i sistemi PMM e RLFP o loro combinazioni, consentivano migliori risultati in termini di potere discriminante, riproducibilità, tipizzabilità, facilità d'esecuzione ed interpretazione.

\section{Criteri di tipizzazione}

I differenti approcci metodologici, le finalità degli indirizzi di ricerca, l'avvento di nuove tecnologie, rendono difficoltoso un inquadramento dei sistemi di tipizzazione, così come eventuali correlazioni o confronti. Il "gold standard" di una tecnica di tipizzazione dovrebbe derivare dall'elevata tipizzabilità, da un alto potere di risoluzione e di riproducibilità (34). Le performance delle varie tecnologie possono essere valutate e confrontate in termini di fattibilità, applicabilità, facilità d'impiego e la validazione di un sistema di tipizzazione dovrebbe quindi prevedere una valutazione delle prestazioni in base ai seguenti criteri (9):

$>$ tipizzabilità (numero di isolati che possono essere tipizzati - 100\%)

$>$ riproducibilità (stabilità del codice identificativo) intra e interlaboratorio

$>$ capacità (potere) discriminante (capacità di differenziare isolati non correlati)

$>$ costo, rapidità e facilità di esecuzione e di interpretazione

Molti di questi caratteri, come ad esempio la capacità discriminante, possono essere espressi numericamente, consentendo più facili comparazioni tra differenti procedure.

Nel considerare e selezionare il marcatore molecolare ottimale, vanno attentamente considerati anche i concetti di spazio e tempo. Studi epidemiologici su piccola scala richiedono un approccio differente da quelli rivolti alla diffusione di particolari microrganismi su scala nazionale o mondiale.

La velocità alla quale il genoma si modifica (orologio molecolare) condiziona $i$ dati generati in base a specifici marcatori molecolari. Tali marcatori vanno quindi selezionati in stretto accordo con lo scopo dello studio (34). A tale proposito, è 
stato proposto di distinguere tre livelli di discriminazione:

1) livello microepidemiologico (nosocomiale) (periodo di giorni/mesi a livello geografico regionale)

2) livello macroepidemiologico (periodo di poche decadi a livello di un paese o continente)

3) livello evoluzionario (periodo di migliaia di anni a livello mondiale)

\section{Capacità discriminante.}

Uno dei sistemi per valutare il potere discriminante di un sistema di tipizzazione è quello di confrontare i dati generati da un metodo con quelli ottenuti da altri metodi, sul medesimo set di isolati. Maggiore è la capacità discriminante di un sistema, maggiore sarà la sensibilità a rilevare mutazioni minori. In merito a ciò, sono stati proposti criteri interpretativi per definire patterns correlati o non correlati, ottenuti con PFGE. Una o due mutazioni possono infatti produrre differenze esprimibili in 3-6 bande elettroforetiche: gli isolati andrebbero considerati correlati se presentano differenze su 1-3 bande, probabilmente correlati se presentano differenze su 4-6 bande. Questo criterio potrebbe però risultare insufficiente: essendo i livelli di mutazione variabili a seconda del microrganismo considerato, un metodo può risultare discriminante per un microrganismo, ma non per un altro. Frequentemente, il potere discriminante di un sistema di tipizzazione viene riportato come numero di tipi ottenuti, comparato al numero d'isolati testati. A questo livello, bisognerebbe calcolare non solo il numero di differenti tipi, ma anche la loro relativa frequenza (stesso numero di tipi ma con frequenza differente).

Per specie ad alto livello di mutazione, per ottenere significative correlazioni epidemiologiche dovrebbero inoltre essere osservati brevi periodi di tempo.

La scelta di un probe specifico è determinante, in particolare utilizzando RFLP: per A. fumigatus, Afut 1 risulta discriminare meglio isolati non correlati e comparando RAPD, Afut 1 -RFLP e MLP è si è evinto che RAPD ha un minore potere discriminante rispetto agli altri due sistemi.

Le tecniche di fingerprinting utilizzabili per $A$. fumigatus richiedono, considerato l'alto grado di variabilità genetica che contraddistingue questa specie, un alto potere discriminante e un elevato grado di riproducibilità. RLFP in combinazione con probe Afut 1 per ibridazione risulta avere un alto potere discriminante ma i tempi e le modalità d'allestimento, associati alle difficoltà d'inter-pretazione, non ne fanno il metodo ideale. Di contro tecniche basate su sequenziamento, come MLST e
CSP, sono al 100\% riproducibili e i dati facilmente interscambiabili, mancando però, per studi su larga scala, di un sufficiente potere discriminante. La capacità discriminante è infatti subordinata alla sequenza scelta: se il livello di variazione nucleotidica non è in grado di dare risposte adeguate da un punto di vista epidemiologico, andrebbero individuati loci più variabili, tenuto conto che l'instabilità genomica dipende dal particolare segmento entro un determinato cromosoma (domains ripetitivi di DNA presentano un grado relativamente alto d'alterazione).

Microsatelliti o short tandem repeats (STRs) mostrano avere un alto livello di discriminazione tra isolati. Recentemente AFLP è stato comparato con STRAf su isolati di 15 pazienti con IA: entrambi i sistemi furono in grado di differenziare 20 genotipi (13). Ancora più di recente un'applicazione basata su 9 short tandem repeats (3 multiplex PCR di ripetizioni di 2,3,4 nucleotidi), denominata STRAf, utilizzata su A. fumigatus, fu in grado di differenziare tutti gli isolati non correlati, innalzando la capacità discriminativa tra $27 \mathrm{x}$ $10^{9}$ differenti genotipi (11). Solitamente le maggiori differenze tra sistemi di tipizzazione si manifestano a livello di interpretazione dei fingerprints ottenuti. I prodotti di amplificazione di STRAf viceversa sono quantificati automaticamente e convertiti in una sequenza numerica: ogni genotipo consiste di una sequenza di nove numeri (3 triplette), facilmente interpretabile. Il potere discriminante di un pannello di microsatellite è aumentato dall'uso di più markers: il pannello di 9 marker usato da de Valk risulta avere maggiore capacità discriminante rispetto a quello di 4 usato da Bart-Delabesse.

\section{Riproducibilità - Interscambiabilità.}

Le tecniche di tipizzazione possono essere grossolanamente divise in due raggruppamenti: quelle basate sul confronto di pattern di bande elettroforetiche e quelle basate su un'esatta collocazione (sequenza) molecolare. Per riproducibilità si intende la capacità della tecnica utilizzata di dare il medesimo risultato in saggi ripetuti. Per sudi di epidemiologia longitudinale o su larga scala sono richieste tecniche che comportino fingerprinting stabili. La maggior fonte d'ambiguità nella valutazione dei risultati è riferibile all'intensità delle bande soggetta a variazioni legate ai vari step che si susseguono nelle procedure. Tecniche esatte (Microsatellite, CSP, MLST), che prescindono da valutazione di pattern di bande elettroforetiche, potenzialmente possono presentare il $100 \%$ di riproducibilità.

In uno studio recente 7 laboratori vollero verificare la riproducibilità interlaboratorio nella tipizza- 
zione di un pannello di A. fumigatus mediante un sistema di sequenziamento single locus. L'analisi comparativa delle sequenze faceva riferimento ad una porzione del locus AFUA, codificante per una proteina di superficie (CSP). Ogni laboratorio utilizzò protocolli differenti di estrazione, PCR e sequenziamento ma i risultati evidenziarono la riproducibilità del sistema (20). Dato aggiuntivo in questa esperienza fu quello di un confronto dei dati via Internet a conferma della possibilità di facili comparazioni interlaboratorio. Un altro importante aspetto che riguarda i sistemi di tipizzazione è proprio quello legato alla possibilità di intersacmbio di dati tra differenti laboratori che garantisca che i genotipi ottenuti presso un centro possano essere comparati con quelli di altri centri, facilitando le conoscenze di un'epidemiologia globale. A tal proposito le tecniche esatte (esatta collocazione molecolare) risulterebbero più adatte, essendo i dati generati con queste tecniche facilmente espressi in un formato digitale. I dati di fingerprinting digitali, viceversa, per la forma dei pattern di banda, sono più complessi e quindi più difficili da interscambiare e confrontare, tenendo conto anche delle difficoltà nella standardizzazione delle procedure. Per MLST gli schemi di numerosi microrganismi sono pubblicati, disponibili e i dati di sequenze alleliche possono essere inviati per verificare il genotipo allelico e ST. Anche per la tipizzazione CPS si possono ottenere risultati analoghi. Un altro vantaggio del metodo basato su microsatelliti è quello legato alla capacità di rilevare isolamenti misti: genotipi misti sono riconosciuti istantaneamente dalla presenza di picchi multipli di differente lunghezza nel marcatore analizzato.

\section{Interpretazione.}

I patterns ottenuti con tecniche basate su confronti di bande possono essere complessi, essendo composti da sequenze più o meno intense o leggere, che rendono difficoltosa la lettura. Anche per un' analisi computerizzata che comporti algoritmi basati su pattern di bande isolate, definite come presenti o assenti, può essere necessaria una lettura visiva, che può essere laboriosa e soggettiva.

A livello di studi comparativi, i risultati potrebbero differire drasticamente in funzione del metodo statistico utilizzato, anche se i moderni programmi computerizzati vengono adattati per la traslazione dei dati di tipizzazione in profili geneticamente coerenti, potendo combinare differenti set di dati di tipizzazione. Dal confronto di pattern viene stabilito che bande con la stessa grandezza contengono lo stesso frammento genetico. Questo assunto può comportare letture scorrette poiché bande della stessa grandezza possono appartenere a frammenti genetici completamente differenti. Di contro tecniche basate su fingerprinting esatti sono più facili da interpretare. Per le tecniche usate in indagini epidemiologiche, tassonomiche ed evolutive, sarebbe auspicabile, in un futuro non lontano, definire una base o piattaforma comune che faciliti la comprensione tra le diverse discipline, attraverso approcci tecnologici di tipizzazione comuni, mediante linee guida unificate, che consentano di interpretare, in maniera corretta, i dati raccolti. Dovrebbero essere inoltre stabiliti, per la standardizzazione e la riproducibilità inter/intra laboratorio, microrganismi o stipiti di riferimento.

\section{Significato clinico.}

L'inalazione di conidi è ritenuta essere la principale via di trasmissione d'infezione. Prima della fase invasiva è necessaria una fase di colonizzazione, in particolare delle basse vie respiratorie, che è considerata importante fattore di rischio, specialmente per soggetti con malattie polmonari croniche. Numerosi studi basati sul sequenziamento sono stati approntati per visualizzare pattern di colonizzazione: da queste osservazioni si è evinta una notevole variabilità genotipica nei pattern di A. fumigatus. L'elevata variabilità genetica di A. fumigatus presenti nell'aria, così come quella di stipiti in campioni respiratori, confermano che gli individui possono essere costantemente esposti ad una grande varietà di differenti genotipi, risultando molto difficoltoso individuare l'origine di un episodio nosocomiale. È stato dimostrato che campioni d'origine respiratoria e ambientale possono contenere genotipi multipli. La variabilità genetica delle altre specie di Aspergillus è meno evidente, tenuto conto anche della minor presenza di conidi nell'ambiente.

La presenza di variabilità genotipica è stata dimostrata anche per altre categorie di pazienti, come quelli trapiantati, con aspergilloma o con IA. Le ripetute applicazioni di metodiche molecolari a campioni di Aspergillus d'isolamento clinico e ambientale hanno consentito di perfigurare uno scenario nel quale il tratto respiratorio possa essere colonizzato da numerosi e differenti genotipi, conseguenza dell'inalazione di conidi, rappresentando questo il primo step verso l'infezione, cui fa seguito la fase invasiva in cui un unico genotipo raggiunge la supremazia e invade $i$ tessuti circostanti ed eventualmente il torrente circolatorio (13). Un isolato ottenuto da campioni respiratori può quindi non necessariamente rappresentare lo stesso genotipo riscontrabile nei tessuti, potendo essere espressione della fase di colonizzazione o semplicemente di una contaminazione ambientale (11). La caratterizzazione molecolare di stipiti di Aspergillus ha consentito infine di verificare le 
reale distribuzione delle specie d'origine clinicoambientale. Confermandosi la prevalenza di $A$. fumigatus quale specie di maggior interesse clinico, non sono mancate le segnalazioni sulla presenza di altre specie, alcune di recente scoperta, il cui significato è ancora da chiarire. Attraverso uno studio di sorveglianza della durata di 6 anni, ad esempio, vennero raccolti 218 stipiti di Aspergillus da pazienti trapiantati, con diagnosi di aspergillosi invasiva provata o probabile. Gli stipiti vennero sottoposti a sequenziamento, usando le regioni ITS e $\beta$-tubulina e, oltre a confermare la prevalenza di A. fumigatus, seguito da $A$. flavus e $A$. niger, vennero descritte nuove specie, come $A$. lentulus e $A$. calidoustus, dotate di MIC in vitro più alte nei confronti di vari antifungini (3).

\section{CONCLUSIONI}

Negli ultimi anni, anche in ambito fungino, i sistemi basati sull'amplificazione e il rilevamento di specifici targets molecolari sono passati dalla fase di ricerca sperimentale a campi d'applicazione diagnostica. Questa evoluzione tecnologicocognitiva ha portato di conseguenza a nuove opportunità e prospettive per la tassonomia e per l'identificazione fungina, basate fino ad un recente passato quasi esclusivamente su valutazioni di carattere fenotipico.

Ancora oggi però non esiste un sistema che non presenti dei limiti nel riconoscimento delle specie: i criteri morfologici e fisiologici, oltre ad essere soggetti a variazioni intra-specie sono spesso sovrapponibili per specie geneticamente distinte, mentre i metodi molecolari non consentono di stabilire con precisione le linee di confine che distinguono microrganismi filogeneticamente correlati. E necessario quindi considerare con attenzione il ruolo che le differenti tipologie di sistemi possono avere per stabilire il confine tra le varie specie, considerando che la tassonomia fungina non dovrebbe limitarsi al riconoscimento della specie ma dovrebbe comprendere una descrizione più ampia, che possa essere utilizzata per identificare un isolato ma anche per comprenderne le prerogative ecologiche e biologiche.

Nella definizione di specie, in questi ultimi anni, ha preso il sopravvento un concetto polifasico di specie e di tassonomia polifasica basato su approccio multidisciplinare, mediante l'integrazione di tutte le informazioni derivate da indagini fenotipiche, genotipiche, filogenetiche: dove precedentemente l'analogia DNA-DNA genomica consentiva di stabilire una guida per l'identificazione di specie, la definizione e i dettagli ottenibili con gli attuali sistemi di tipizzazione, consente di stabilire inquadramenti tassonomici più coerenti, riducendo il gap tra tassonomia da un lato, genetica evolutiva ed epidemiologia microbica dall'altro.

In riferimento ai metodi di tipizzazione, sebbene attualmente ci si possa avvalere di differenti tecnologie utilizzando marcatori multipli, non vanno persi di vista i criteri cardine sui quali basare le nostre osservazioni, quali capacità discriminante, riproducibilità e tipizzabilità, tenendo conto che la variabilità nella marcatura genetica, attraverso la quale vengono stabiliti i livelli di restrizione di specie, subspecie o isolato, può essere impiegata per stabilire il livello di suddivisione tra popolazioni.

Sempre a livello di tipizzazione, come già ricordato precedentemente, nel considerare e selezionare il marcatore molecolare ottimale, vanno attentamente considerati anche i concetti di spazio e tempo, in quanto studi epidemiologici su piccola scala e di livello microepidemiologico riferibili a periodi di tempo limitati (giorni o mesi), necessitano di un approccio differente rispetto a quelli emiologico-evolutivi riferibili a periodi di tempo decisamente più lunghi.

\section{BIBLIOGRAFIA}

1. Aufauvre-Brown A, Cohen J, Holden DW. Use of randomly amplified polymorphic DNA markers to distinguish isolates of Aspergillus fumigatus. J Clin Microbiol 1992 Nov; 30 (11): 2991-3.

2. Bain JM, Tavanti A, Davidson AD, Jacobsen MD, Shaw D, Gow NA, Odds FC. "Multilocus sequence typing of the pathogenic fungus Aspergillus fumigatus". J Clin Microbiol 2007 May; 45 (5): 1469-77. Epub 2007 Mar 21

3. Balajee S. A., Borman A. M., Brandt M. E., Cano J., Cuenca-Estrella M., Dannaoui E., Guarro J., Haase G., Kibbler C. C., Meyer W., O’Donnell K., A. Petti C., Rodriguez-Tudela J. L., Sutton D., Velegraki A., Wickes B. L. "Sequence-Based Identification of Aspergillus, Fusarium, and Mucorales Species in the Clinical Mycology Laboratory: Where Are We and Where Should We Go from Here?" J Clin Microbiol 2009 April, 47 (4): 877-884

4. Balajee SA, Gribskov JL, Hanley E, Nickle D, Marr KA. "Aspergillus lentulus sp. nov., a new sibling species of Aspergillus fumigatus" Eukaryot Cell 2005 Mar; 4 (3): 625-32

5. Balajee SA, Nickle D, Varga J, Marr KA. "Molecular studies reveal frequent misidentification of Aspergillus fumigatus by morphotyping" Eukaryot Cell 2006 Oct; 5 (10): 1705-12.

6. Balajee S.A., Sun T. Tay S.T., Lasker B.A., Hurst S.F., Rooney A.P. "Characterization of a Novel Gene for Strain Typing Reveals Substructuring of Aspergillus fumigatus across North America" Eukaryotic Cell August 2007, p. 1392-1399, Vol. 6, No. 8

7. Bart-Delabesse E, Humbert JF, Delabesse E, Bretagne S. "Microsatellite markers for typing Aspergillus fumigatus isolates" J Clin Microbiol 1998 September; 36 (9): 2413-2418

8. Bertout S, Renaud F, Barton R, Symoens F, Burnod J, Piens MA, Lebeau B, Viviani MA, Chapuis F, Bastide 
JM, Grillot R, Mallié M; European Research Group on Biotype and Genotype of Aspergillus "Genetic polymorphism of Aspergillus fumigatus in clinical samples from patients with invasive aspergillosis: investigation using multiple typing methods" J Clin Microbiol 2001 May; 39 (5): 1731-7

9. Blanc D.S., Hauser PM., Francioli P., Bille J. "Molecular typing methods and their discriminatory power" Clinical Microbiol Infect 1998, 4 (2): 61-63

10. Denning DW, Clemons KV, Hanson LH, Stevens DA. "Restriction endonuclease analysis of total cellular DNA of Aspergillus fumigatus isolates of geographically and epidemiologically diverse origin, $J$ Infect Dis. 1990 Nov; 162 (5): 1151-8.

11. de Valk HA "Exact Molecular Typing of Aspergillus fumigatus. Methods and Applications" 2008

12. de Valk HA, Meis JF, Curfs IM, Muehlethaler K, Mouton JW, Klaassen CH. "Use of a novel panel of nine short tandem repeats for exact and high-resolution fingerprinting of Aspergillus fumigatus isolates" $J$ Clin Microbiol 2005 Aug; 43 (8): 4112-20.

13. de Valk HA, Meis JF, Klaassen CH. "Microsatellite based typing of Aspergillus fumigatus: strengths, pitfalls and solutions" J Microbiol Methods 2007 May; 69 (2): 268-72. Epub 2007 Jan 31

14. Diaz-Guerra TM, Mellado E, Cuenca-Estrella M, Gaztelurrutia L, Navarro JI, Tudela JL. "Genetic similarity among one Aspergillus flavus strain isolated from a patient who underwent heart surgery and two environmental strains obtained from the operating room” J Clin Microbiol 2000 Jun; 38 (6): 2419-22.

15. de Vries RP, Frisvad JC, van de Vondervoort PJ, Burgers K, Kuijpers AF, Samson RA, Visser J. "Aspergillus vadensis, a new species of the group of black Aspergilli" Antonie Van Leeuwenhoek 2005 Apr; 87 (3): 195-203.

16. Etienne KA, Kano R, Balajee SA. "Development and validation of a microsphere-based Luminex assay for rapid identification of clinically relevant aspergilli" $J$ Clin Microbiol 2009 Apr; 47 (4): 1096-100. Epub 2009 Feb 25

17. Frisvad JC, Larsen TO, de Vries R, Meijer M, Houbraken J, Cabañes FJ, Ehrlich K, Samson RA." Secondary metabolite profiling, growth profiles and other tools for species recognition and important Aspergillus mycotoxins" Stud Mycol 2007; 59: 31-7.

18. Geiser DM, Klich MA, Frisvad JC, Peterson SW, Varga J, Samson RA. "The current status of species recognition and identification in Aspergillus" Stud Mycol 2007; 59: 1-10

19. Henry T, Iwen PC, Hinrichs SH. "Identification of Aspergillus species using internal transcribed spacer regions 1 and 2" J Clin Microbiol 2000 Apr; 38 (4): 1510-5

20. Hurst SF, Kidd SE, Morrissey CO, Snelders E, Melchers WJ, Castelli MV, Mellado E, Simmon K, Petti CA, Richardson S, Zhang S, Romanelli AM, Wickes BL, de Valk HA, Klaassen $\mathrm{CH}$, Balajee SA. "Interlaboratory reproducibility of a single-locus sequence-based method for strain typing of Aspergillus fumigatus" J Clin Microbiol 2009 May; 47 (5): 1562-4. Epub 2009 Mar 4

21. Klaassen CH, Osherov N. "Aspergillus strain typing in the genomics era" Stud Mycol 2007; 59: 47-51

22. Lasker BA. "Evaluation of performance of four genotypic methods for studying the genetic epidemiology of Aspergillus fumigatus isolates" J Clin Microbiol. 2002 Aug; 40 (8): 2886-92

23. Levdansky E, Romano J, Shadkchan Y, Sharon H, VerstrepenK.J., Fink G.R., Osherov N. "Coding
Tandem Repeats Generate Diversity in Aspergillus fumigatus Genes" Eukaryotic Cell August 2007, p. 1380-1391, Vol. 6, No. 8

24. Magee PT, Bowdin L, Staudinger J. "Comparison of molecular typing methods for Candida albicans" $J$ Clin Microbiol 1992 Oct; 30 (10): 2674-9

25. Montiel D, Dickinson MJ, Lee HA, Dyer PS, Jeenes DJ, Roberts IN, James S, Fuller LJ, Matsuchima K, Archer DB. "Genetic differentiation of the Aspergillus section Flavi complex using AFLP fingerprints" Mycol Res 2003 Dec;107 (Pt 12): 1427-34

26. Moody SF, Tyler BM. "Restriction enzyme analysis of mitochondrial DNA of the Aspergillus flavus group: A. flavus, A. parasiticus, and A. nomius" Appl Environ Microbiol 1990 Aug; 56 (8): 2441-52.

27. Perrone G, Susca A, Epifani F, Mulè G. "AFLP characterization of Southern Europe population of Aspergillus Section Nigri from grapes" Int J Food Microbiol 2006 Sep 1;111 Suppl 1:S22-7. Epub 2006 May 8.

28. Raclaský V, Trtková J, Rusková L, Buchta V, Bolehovská R, Vacková M, Hamal P. "Primer R108 performs best in the RAPD strain typing of three Aspergillus species frequently isolated from patients" Folia Microbiol (Praha) 2006; 51 (2): 136-40

29. Rath PM, Petermeier K, Verweij PE, Ansorg R. "Differentiation of Aspergillus ustus strains by random amplification of polymorphic DNA" J Clin Microbiol 2002 Jun; 40 (06): 2331-3

30. Rodriguez E, Symoens F, Mondon P, Mallie M, Piens MA, Lebeau B, Tortorano AM, Chaib F, Carlotti A, Villard J, Viviani MA, Chapuis F, Nolard N, Grillot R, Bastide JM. "Combination of three typing methods for the molecular epidemiology of Aspergillus fumigatus infections. European Research Group on Biotype and Genotype of Aspergillus" J Med Microbiol 1999 Feb; 48 (2): 181-94

31. Samson, R. A.;Varga, J. "What is a species in Aspergillus?" Medical Mycology, Volume 47, Supplement 12009 , pp. 13-20 (8)

32. Staab JF, Balajee SA, Marr KA. “Aspergillus section Fumigati typing by PCR-restriction fragment polymorphism" J Clin Microbiol 2009 Jul; 47 (7): 207983. Epub 2009 Apr 29.

33. Tran-Dinh N, Carter D. "Characterization of microsatellite loci in the aflatoxigenic fungi Aspergillus flavus and Aspergillus parasiticus" Mol Ecol 2000 Dec; 9 (12): 2170-2.

34. van Belkum A, Struelens M, de Visser A, Verbrugh $H$, Tibayrenc M. "Role of genomic typing in taxonomy, evolutionary genetics, and microbial epidemiology" Clin Microbiol Rev 2001 Jul; 14 (3): 547-60

35. Vandamme P, Pot B, Gillis M, de Vos P, Kersters K, Swings J. "Polyphasic taxonomy, a consensus approach to bacterial systematics" Microbiol Rev 1996 Jun; 60 (2): 407-38.

36. James M. J.,. Lasker B. A, McNeil M. M, Shelton M., Warnock D. W., Reiss E. "Use of a repetitive DNA probe to type clinical and environmental isolates of Aspergillus flavus from a cluster of cutaneous infections in a neonatal intensive care unit" $J$ Clin Microbiol 2000 October; 38 (10): 3612-3618

37. Warris A, Klaassen CH, Meis JF, De Ruiter MT, De Valk HA, Abrahamsen TG, Gaustad P, Verweij PE. "Molecular epidemiology of Aspergillus fumigatus isolates recovered from water, air, and patients shows two clusters of genetically distinct strains" J Clin Microbiol 2003 Sep; 41 (9): 4101-6

38. Wengenack NL, Binnicker MJ. "Fungal molecular diagnostics" Clin Chest Med 2009 Jun; 30 (2): 391 408 . 